\title{
Populistas y populismos en el Perú. Una aproximación bibliográfica
}

Populistas and Populisms in Peru. A Bibliografical Approch

Javier Iván Saravia Salazar ${ }^{1}$

Universidad Científica del Sur, Lima, Perú

javiersaraviasal@gmail.com

\section{RESUMEN}

Este artículo busca aproximar al lector al estado actual de los estudios sobre el populismo en nuestro país, y dar cuenta de cómo el debate sobre él ha sido postergado en el Perú en comparación con la región, donde la aparición de líderes de tendencias de izquierda ha actualizado el debate. Muchos son los gobiernos tildados con este rótulo, por lo que han hecho impreciso el término y muy discutible su aplicación al análisis político. Sin embargo, su constante aparición en el debate público ya académico evidencian su actualidad y relación, más que oposición, con el sistema democrático.

\section{PALABRAS CLAVE}

Populismo, democracia, siglos XIX y XX, caudillismo, Ernesto Laclau

\section{ABSTRACT}

This article seeks to bring the reader to the current state of research on populism in our country, also give an account of how the debate over it has been delayed in Peru compared with the region. Where the emergence of leftlearning leaders updated the debate. Many governments are branded with this label have done so vague term and very questionable application to political analysis, but its constant appearance in public debate and academic demonstrate its relevance and value, rather tan opposition to the democratic system.

1 Historiador y docente del Área de Cursos Básicos de la Universidad Científica del Sur. Está a cargo de los cursos de Realidad Nacional (pregrado) e Historia del Perú y del Mundo (Programa Beca 18). 


\section{KEYWORDS}

Populism, democracy, XIXs and XX centuries, caudillismo, Ernesto Laclau

\section{Introducción}

Un libro relativamente reciente, El eterno retorno del populismo en América Latina y el Caribe (2012), pone en evidencia el vivo debate que aún existe sobre el tema tanto en su intento de conceptualización como en el de su aplicabilidad para el análisis político. La presencia de regímenes de retórica socialista y de arrastre popular elegidos democráticamente en la región en las pasadas décadas reabrió intensamente el debate. Se habla peyorativamente de un regreso del populismo a la región ${ }^{2}$, el cual habría reaparecido desde la década de 1990 en forma de populismo neoliberal (o neopopulismo), vinculado a la derecha, y que desde finales del siglo XX en adelante es reemplazado por un populismo de izquierda más cercano al populismo original (o histórico) de la década de 1960.

Esta supuesta reaparición del temido populismo en la región estaría asociada a las consecuencias negativas de las políticas neoliberales en su apuesta ciega por el desarrollo económico y la mano invisible del mercado. Como opina Emir Sader, las nuevas experiencias políticas vienen a poner en cuestión el «sentido común neoliberal» ${ }^{3}$. Las ciencias sociales en la región en general han catalogado a estos fenómenos como «nuevos gobiernos de izquierda» o simplemente como «gobiernos populistas» (Reano, 2012, p. 61).

El populismo en América Latina ha resurgido como un fértil campo de investigación teórica para los estudiosos de las ciencias sociales, la democracia y la filosofía política. En contraposición a esta tendencia actual de las ciencias sociales en la región, en el Perú el tema del populismo ha sido dejado de lado por la academia y ha sido poco estudiado desde la década de 1990 en adelante. A tal punto que el debate sobre él se centra en los medios de comunicación, que difunden una visión esencialmente negativa del populismo al encasillarlo como un discurso clientelista, retrógrado, autoritario, improvisado, coyuntural y antidemocrático.

2 Como ejemplo de este resurgir del tema está el seminario de investigación de Flacso en México «Populismo, buen gobierno y justicia social» creado en 2005. Este seminario editó tres importantes libros: Vox populi: Populismo y democracia en América Latina (2007), Política y sociedad en México. Entre el desencuentro y la ruptura (2008) y ¿Autoritarismo y democracia? Hugo Chávez y Evo Morales (2009). A partir de 2010, el seminario cambió de nombre a «Procesos políticos contemporáneos de Latinoamérica».

3 El Nuevo topo: los caminos de la izquierda latinoamericana. Buenos Aires: Siglo XXI. 
En las siguientes líneas haremos un recorrido por los orígenes del concepto y por cómo ha sido abordado tanto por sociólogos e historiadores, ofreceremos un recuento de los textos recientes sobre el tema para el caso peruano, y finalmente veremos la manera en que el populismo se inserta en el debate de la democracia. Debemos precisar que nuestro enfoque y la selección de la bibliografía se ha hecho desde la lectura de los gobiernos llamados populistas.

\section{Origen del concepto}

Hacia finales del siglo XIX podemos encontrar dos denominaciones de populismo, uno vinculado al Partido del Pueblo de Estados Unidos y otra versión vinculada a la crítica marxista.

\section{El partido del pueblo}

El término populismo fue usado originalmente en Estados Unidos a mediados de la década de $1890^{4}$, en referencia al Partido del Pueblo ${ }^{5}(\mathrm{~Pa}-$ nizza, 2009, p. 9), pero desde entonces casi ningún movimiento o líder ha reconocido ser «populista». En el lenguaje político corriente, el término posee una connotación negativa, al estar estrechamente asociado con términos como demagogia y prodigalidad económica, que indican irresponsabilidad económica o política. Eric Hobsbawm señala que:

Es característico de la situación de los Estados Unidos en los años treinta que el populismo demagógico de mayor éxito, y tal vez el más peligroso de la década, la conquista de Luisiana por Huey Long, procediera de lo que era, en el contexto norteamericano, una tradición radical y de izquierdas [las cursivas son nuestras] (Hobsbawm, 1998, p. 139).

Charles Postel (2007) pone énfasis en el papel del populismo como una manifestación de la modernidad más que un rezago al cambio y propuesta antimoderna. Sobre el particular, nos dice sobre los activistas del Partido del Pueblo:

4 Adolfo Castañón (2006), sin embargo, le asigna un origen más tardío al vocablo. Nos dice que: «La voz populismo se registra por primera vez en 1929. Proviene del latín populos: "pueblo". Fue acuñada en el contexto de una escuela literaria que aspiraba a describir en la novela la vida de los hombres del pueblo. Le Grand Robert: Dictionnaire de la Langue Française cita un manual de estudios literarios de los autores Castex y Surer, donde se explica que hacia 1928 el escritor Léon Lemonnier, queriendo reaccionar contra la novelística aristocrática y mundana, fundó junto a André Thérive la escuela populista y definió sus intenciones en dos manifiestos, en agosto de 1929 y en enero de 1930. Se trataba de pintar la vida de la pobre gente, pero de pintarla con mesura y verdad, sin caer en los excesos y en las ideas preconcebidas del naturalismo.

5 El libro más completo sobre el Partido del Pueblo es de The Populist Vision, de Charles Postel. 
But were they? This work of historical excavation suggests otherwise. And that is what makes the experience of the Populism so relevant. The populists challenged the corporate frameworks. They protested the inequitable distribution of wealth. They demanded more responsive gobernment. But they too, were modern (Postel, 2007, p. viii).

Es decir, el fenómeno populista desde su origen surge dentro de un contexto democrático, de boom económico y de desigualdad en la distribución de la riqueza económica. No es, por tanto, un fenómeno reñido per se con la democracia; es una manifestación de ella, así como una exigencia de la ampliación de sus beneficios directos y conexos a un mayor número de ciudadanos.

\section{La tradición marxista}

En la terminología marxista de mitad del siglo XX, populismo aparece como traducción en lenguas occidentales del ruso narodnik (narodismo), en referencia al movimiento Narodnik Volya (Voluntad Popular). Este movimiento revolucionario ruso de fines del siglo XIX defendía una democracia social basada en el beneficio de los pequeños productores rurales y artesanales, y se oponía al mismo tiempo a la oligarquía zarista y a los principios marxistas. Justamente fue en la polémica suscitada entre narodistas y marxistas rusos que el joven Lenin, en una serie de textos publicados en 1894 y 1897, expuso las contradicciones internas del discurso narodista aplicándole adjetivos como subjetivistas, superficiales, románticos, embelesados, inmaduros y otros similares, que ponen en relieve la irracionalidad de los enunciados de estos supuestos «amigos del pueblo». Lenin anticipó en su condena al narodismo los juicios de valor que en el futuro se destinarían a las experiencias políticas rotuladas similarmente de populismo.

Oscar Chamosa (2013) señala que, a pesar de la connotación negativa que el término populismo adquirió gracias a Lenin, los autores marxistas europeos se abstuvieron de aplicarlo en forma indiscriminada. Es con el triunfo bolchevique que el populismo se convirtió en un sujeto de especulación histórica antes que un problema político presente. A lo largo de los años 20 y comienzos de los 30, los líderes marxistas europeos concentraron su crítica en sus dos enemigos presentes, la social democracia y el fascismo, pero a ninguno de ellos les endilgó el mote de populista.

\section{2. ¿De qué hablamos cuando hablamos de populismo?}

El populismo ha sido abordado, a lo largo del tiempo, desde distintas perspectivas analíticas. Mientras que algunos lo han analizado como una etapa vinculada a los procesos de modernización de los países periféricos (G. Germani, I. Ionescu y E. Gellner); otros lo ligan con el papel del Estado, 
ya sea para introducir al capital y las clases sociales en la transición hacia el capitalismo (O. lanni), para garantizar el desarrollo dependiente (F. E. Cardoso y E. Faletto), o para apoyar a las burguesías, débiles a la hora de imponer su hegemonía (F. Weffort y A. Quijano); algunos lo analizan como un tipo particular de discurso político (E. De Ippola, S. Sigal y E. Verón); como una experiencia política particular de los sectores populares (D. James, D. Martuccelli y M. Svampa); como una forma de articulación entre la política y la economía (R. Dornbush y S. Edwards); como una construcción académica que, paradójicamente, señala las limitaciones de los propios académicos a la hora de intentar resolver los fantasmas creados por su propia imaginación (G. Olivera). Algunos creen que no existe el populismo sino populismos (M. Canovan), mientras que otros son pródigos a la hora de proyectarlo hacia el futuro en función de los avances de la sociedad contemporánea, y se habla entonces de populismo posmoderno (P. Taguieff).

A pesar de que esta lista no resulte definitiva (ni mucho menos), nos permite afirmar que hay tantas concepciones del populismo como enfoques académicos, visiones ideológicas e, incluso, modas intelectuales existentes. A partir de la variedad de autores y posiciones mencionadas, con el tiempo se produjo un ocultamiento del concepto que llevó, casi automáticamente, a pensar al populismo según uno u otro referente. Parecería imposible abordar al populismo como fenómeno en sí. Dicho ocultamiento, sin embargo, pone de manifiesto el punto ciego de la reflexión sobre el populismo: la falta de un acuerdo básico sobre sus elementos definitorios. De esa forma, el populismo se transformó en una «etiqueta política», que designa una amplia gama de fenómenos, partidos, movimientos, líderes democráticos y autoritarios de distintas épocas, lugares y afiliaciones ideológicas. Evidentemente, cuando todo se transforma (o puede transformarse) en populismo, hemos perdido la especificidad descriptiva del concepto. Dicho estiramiento conceptual, a la larga, constituye uno de los principales obstáculos en la reflexión sobre el tema.

Francisco Pazzini (2009) distingue tres modos de aproximación teórica y analítica al populismo: a) generalizaciones empíricas, b) explicaciones historicistas, y c) interpretaciones sintomáticas. Esta clasificación no ha sido adoptada del todo por la comunidad académica pero nos parece bastante útil para circunscribir el último momento de análisis del populismo al vincularse directamente a la praxis civil en la política (interpretaciones sintomáticas) ${ }^{6}$.

6 En esta línea de ideas puede situarse el artículo de Juan Carlos Ubillús citado en la bibliografía. 


\section{Laclau en escena ${ }^{7}$}

En 2005, Ernesto Laclau dio a conocer su obra La razón populista, que retomaba y profundizaba sus aportaciones anteriores sobre el tema. Ya en 1977, Laclau había publicado un texto sobre la misma cuestión, el cual alcanzó amplia repercusión, posicionando a su autor como un referente obligado sobre el tema. La obra en mención era Politics and Ideology in Marxist Theory: Capitalism, Fascism, Populism ${ }^{8}$. El texto, al tiempo que retoma la temática del populismo, profundiza algunos puntos significativos en la obra de Laclau. Por tal motivo, La razón populista es un texto que integra de forma coherente y provocativa el resultado de años de trabajo.

Se analiza al populismo como una lógica discursiva particular, que puede ser desarrollada en el contexto de diferentes tipos de organizaciones e ideologías políticas. Para Laclau, el populismo presenta una forma de articulación de las demandas sociales a partir de la cual se constituye la unidad de un grupo político y con ello, se da lugar al surgimiento de una lógica determinada. Por lo tanto, el populismo es una lógica política, entendiendo por ello un sistema de reglas que articulan un horizonte dentro del cual algunos objetos son representados mientras que otros están excluidos, y generan un proceso de significaciones que solo puede ser comprendido en su propio contexto. La importancia de las lógicas políticas reside en que instituyen lo social, no de forma arbitraria, sino a partir de una determinada articulación de las demandas sociales. Esta articulación, que puede llevarse a cabo tanto a través de la lógica de la diferencia como de la equivalencia, presupone la constitución de un sujeto político.

\section{El populismo clásico}

El populismo clásico o histórico es como la «academia» se ha referido a las apariciones populistas en la región y nos remite a líderes de la región como Getúlio Vargas (Brasil) y Juan Domingo Perón (Argentina). Representó un movimiento político urbano que se oponía al statu quo basado en la exportación de productos primarios vigente desde el siglo XIX, y que proponía en cambio un acelerado desarrollo industrial. Formó

7 Los recientes triunfos electorales de Podemos en España y Syriza en Grecia, cuyos líderes fueron influenciados por el pensamiento de Ernesto Laclau, ponen en evidencia las posibilidades prácticas de su modelo de "articulación de demandas». La eficacia y éxito de estos regímenes como propuestas políticas duraderas dependerá de su capacidad de liderazgo al hacer frente a las condiciones económicas adversas por las que atraviesan ambos países. Consúltese http://www.revistaenie.clarin.com/ideas/Laclau-populismo-indignados_0_1307869214.html

8 La edición traducida al español data de 1978, Política e ideología en la teoría marxista: Capitalismo, fascismo, populismo. Madrid: Siglo XXI. La obra fue traducida, además, al alemán, griego y portugués. 
alianzas, uniendo la clase obrera a la burguesía industrial, y minimizó los antagonismos entre clases propagando una ideología nacionalista en general (Cardoso y Helwege, 1993).

El populismo clásico favoreció a los gobiernos activistas decididos a desempeñar un papel importante en la determinación de precios, la protección de trabajadores y salarios, la política de alimentos baratos, la propiedad de industrias clave por el Estado, la asignación estatal de crédito con bajas tasas de interés, y a favorecer la industria privada. Rechazaba toda apelación de la necesidad de poner controles generales al gasto. Sus consecuencias fueron un extenso crecimiento del gobierno respecto del sector privado y una generalizada corrupción en diversas formas, incluyendo la evasión de impuestos. Crecientes déficits presupuestarios resultaron en enormes deudas externas. La sustitución de importaciones asociada a las restricciones al comercio hizo depender a los países del capital extranjero. La tendencia urbana de política económica y asignación de recursos solo acentuó la pobreza de los campos.

Economistas y politólogos de derecha y de izquierda han subrayado los aspectos negativos del populismo. La derecha tilda a los populistas de demagogos que desencadenan la inflación, atemorizan a los capitalistas y provocan inestabilidad política. La izquierda los acusa de traicionar a las masas. Pero la mayoría de los regímenes populistas no se propusieron efectuar una revolución, como en el Chile de Allende o la Nicaragua de Ortega. Los populistas esperaban reformar el sistema, no derrocarlo. Su programa consistía en lograr un crecimiento económico basado en la industrialización, como camino hacia un empleo sostenido. Abrumado por sus errores, se suele olvidar que el modelo de sustitución de importaciones (ISI) en América Latina produjo más de 5\% anual entre 1950 y $1980^{\circ}$.

El programa de redistribución de los populistas clásicos no fue sostenible por las mismas razones por las que, a la postre, fracasó el ISI. EI proteccionismo no elevó lo bastante la productividad real para crear una base de grandes ganancias en los salarios urbanos. Tampoco el cobro de impuestos creció lo necesario para financiar el subsidio del proceso de industrialización por el gobierno. Se sobreestimó la rigidez de la oferta en los sectores agrícola y de exportaciones: los sobrevaluados tipos de cambio y los controles de precio no tardaron mucho tiempo en causar un estancamiento en estos sectores. La alienación del capital extranjero solo

9 El programa de distribución de los populistas pedía un aumento de los ingresos urbanos a expensas de los productos rurales, los exportadores y el capital extranjero. Juan Velasco Alvarado promovió una la reforma agraria, pero su política de créditos y de precios favorecieron a los sectores urbanos. 
vino a exacerbar estos problemas. A falta de un gran auge de los precios de exportación, el populismo clásico pronto se destruyó a sí mismo.

\section{Imprecisión conceptual}

El concepto de populismo es impreciso, como bien han señalado autores como Francisco Panizza (2009), Gerardo Aboy (2001) y Oscar Chamosa (2013). Se ha vuelto un cliché escribir sobre el populismo lamentando su falta de claridad conceptual y poniendo en duda su utilidad para el análisis político, lo que lo convierte más que en un término en una atribución analítica.

En el Perú la situación no es muy diferente. El debate ha estado más en manos de sociólogos que de historiadores ${ }^{10}$ : los primeros lo han dirigido asignándole al populismo un espacio histórico temporal en las décadas de 1950 y 1960 (populismo histórico). Se ha entendido al populismo de dos maneras: 1) vinculando el análisis del populismo en oposición a la democracia como una manifestación contraria a dicho sistema, y 2) como la «versión latinoamericana» del este sistema ${ }^{11}$. El concepto que quizás mayor influencia tenga sea el de propuesto por Julio Cotler (1969):

[...] movimiento pluriclasista, que a través de relaciones de clientela manipula a las masas populares en proceso de adaptación urbana, por medio de símbolos carismáticos y a fin de incorporarlos al sistema social existente por vías de la ocupación y el consenso. Persigue el establecimiento de una convivencia entre diferentes sectores de la sociedad, ampliando las bases de la ocupación y consumo de la población, a través de la labor de modernización del país, que consiste fundamentalmente en impulsar el proceso de modernización.

Los historiadores, por su parte, se han aventurado tímidamente a esbozar opiniones sobre el concepto, adhiriéndose a los análisis de turno o empleándolos en sus variantes más generales. Se resalta del populismo las características autoritarias del Poder Ejecutivo, cierto protagonismo de las masas populares y un mayor gasto estatal en programas sociales.

\section{Una historiografía del populismo en el Perú}

Diversos gobiernos y gobernantes, de finales del siglo XIX en adelante, tanto democráticos como dictatoriales, han sido tildados de populistas al presentar alguna o algunas de las características antes enunciadas, sin importar que sus programas políticos e intereses fueran muy diferentes $y$

10 Característica común a todos los países de la región.

11 No obstante, la oposición de estas perspectivas se basan casi en los mismos factores para fundamentar sus resultados. Destacan entre ellos la herencia colonial y el autoritarismo. 
muchas veces antagónicos entre sí. Al agruparse de esta manera regímenes tan heterogéneos, se ha resaltado sobremanera el protagonismo de los líderes populistas en medio de la euforia popular generalizada, y se ha caracterizado a la masa electoral ciudadana como irracional, emocional y clientelista. Por ello, la articulación política y social que permitió el triunfo electoral y la legitimidad de estos líderes pasa a un segundo plano en el análisis, avasalladas por las explicaciones de carácter macroeconómico, el análisis político de las élites y en cierta manera el prejuicio generalizado de subestimar al electorado en sus elecciones políticas.

La imagen del líder populista ha invisibilizado procesos complejos de la sociedad peruana en su camino o lucha por una vida democrática. Estos líderes encontraron canales discursivos para articular a la sociedad civil en un proyecto de Estado, pero además existía (y existe) una sociedad civil cuyas demandas no son satisfechas por el Estado, por lo que se articulan social y políticamente para construir modelos democráticos alternativos. Tanto líderes populistas como sociedad civil se desenvuelven dentro de un diseño institucional con reglas que ponen límites a su accionar. Estos tres campos de análisis han sido abordados más de manera aislada que complementara por lo que se tiende a desdibujar el fenómeno cayendo en explicaciones parciales.

La calidad de los trabajos es desigual y la reflexión teórica muchas veces repite puntos comunes; no obstante ello, se ha buscado rastrear los orígenes del populismo en el país y a los representantes del modelo "populista tipo». Los resultados han sido desconcertantes: se ha puesto el rótulo populista a regímenes tan diferentes entre sí como lo fueron los de Nicolás de Piérola, Luis M. Sánchez Cerro, Guillermo Billinghurst, Juan Velasco Alvarado, Fernando Belaunde Terry, Alan García o Alberto Fujimori. Inclusive el actual gobierno de Ollanta Humala fue tildado de populista durante su primer año de gobierno ${ }^{12}$. Aunque algunos científicos sociales y analistas políticos han usado diferentes conceptos de populismo para definir el particular populismo de cada uno de ellos, la regla general ha sido la de encasillar a todos dentro de un megaconcepto de populismo al resaltarse los aspectos autoritarios de estos gobernantes.

Las variantes que hemos detectado son las siguientes: Steve Stein (1980) define a Nicolás de Piérola como un protopopulista, mientras el historiador Alejandro Salinas (2014) y Nils Jacobsen (2014) consideran al

12 El temor ante un eventual «líder populista» fue expresamente materializado en la prensa escrita y televisiva que asediaron al entonces candidato nacionalista. El vertiginoso cambio en la política de gobierno de Ollanta Humala de la Gran Transformación a la Hoja de Ruta disipó el temor o expectativa de un gobierno de corte populista. 
Califa como populista a secas. Jorge Basadre consideraba a Guillermo BiIlinghurst como populista, y los sociólogos Peter Blanchard (1982) y Osmar Gonzales (2005) encuentran los orígenes del populismo peruano en él; comparten esta idea los historiadores Humberto Leceta (2001) y Luis Alberto Torrejón (2010). El investigador norteamericano David Palmer (1980) considera a Augusto B. Leguía como un populista siguiendo los patrones del caudillismo decimonónico. Para el periodo de la década de 1930 tenemos que el sociólogo Manuel Castillo (1990) se refiere a la propuesta política de Luis M. Sánchez Cerro como un «populismo autoritario», «populismo conservador» o de «derecha»; el historiador Paul Drinot (2001) comparte esta posición. La socióloga María Josefina Huamán VaIladares (1974), a contracorriente, cuestiona la denominación de populista al APRA para el periodo 1930-1945. El historiador Emilio Iván Candela Jiménez (2013) encuentra en el gobierno de Óscar R. Benavides prácticas populistas. Existe unanimidad en señalar a la primera etapa del Gobierno de las Fuerzas Armadas con Juan Velasco Alvarado como populista. Los autores que más han desarrollado el tema son los sociólogos Julio Cotler (1969), Nicolás Lynch (2009) y Sinesio López ${ }^{13}$. El análisis negativo del «populismo económico» de Alan García reúne a científicos sociales y economistas, entre ellos Eliana Cardoso y Ana Helwege, Carlos Boloña Behr ${ }^{14}$, John Crabtree (1992) y Henry Pease $(1988)^{15}$. Aldo Panfichi y Cinthia Sanborn (1997), John Crabtree (1998), entre otros investigadores de formación norteamericana, entienden la política de la dictadura de Fujimori como neopopulista ${ }^{16,17}$.

\footnotetext{
13 En numerosos textos y conferencias, Sinesio López se ha referido al régimen velasquista como populista. Puede consultarse Ciudadanos reales e imaginarios: concepciones, desarrollo y mapa de la ciudadanía en el Perú (1997).

14 Los trabajos del economista destinados al gran público más que a la academia reforzaron la visión negativa del populismo. Ver Cambio de rumbo (1993) y Lecciones de economía (1999). 15 En esta forma de ver el populismo el acento está puesto en la falta de responsabilidad fiscal y de planificación; se resalta el carácter irracional del populismo, así como de las naciones que lo adoptan como modelo. Oscar Chamosa (2013) señala que «de alguna manera, esta versión de populismo es la del economista británico Peter Wiles, quien en 1967 definió el populismo como un síndrome antes que un programa». El trabajo de Wiles a la que nos remite el historiador argentino es «Populism: A Syndrome not a Doctrine». En lonescu, G. y Gellner, E. (Coord.). Populism. Its Meaning and National Characteristics. Londres: Macmillan, pp. 163-79. Ilustrativo de esta manera de ver el populismo es el libro del abogado José Luis Sardón (2013). Democracia sin populismo: cómo lograrlo. Madrid: Unión Editorial.

16 Nos adherimos a la opinión de Nicolás Lynch de considerar que no existe una vinculación entre el asistencialismo de Fujimori y del sistema neoliberal al llamado por al autor populismo clásico, porque dentro del programa neoliberal existe un programa focalizado de asistencia a poblaciones vulnerables (extrema pobreza) y esta asistencia focalizada no significa necesariamente una ampliación de derechos. Esto hecho, le guste o no a sus críticos, es una característica de los populismos históricos (Lynch, 2000).

17 Mención aparte merece la tesis de Mariana Alvarado Chávez (2009). La invención del etnocacerismo: populismo radical en el Perú (tesis de maestría en Ciencia Política con mención en Política Comparada). Pontificia Universidad Católica del Perú, Lima. En ella destaca el perfil autoritario del etnocacerismo de Antauro Humala y se vale del concepto de populismo radical
} 


\section{Populismo y democracia}

El «corto siglo $X X$ » peruano, parafraseando a Hosbawm, presentó acontecimientos diversos de difícil periodificación, por la variada naturaleza de los hechos acaecidos: golpes de Estado, dictaduras, periodos de transición democrática, expansión de derechos ciudadanos, cambios de modelo económico, explosión demográfica. La periodificación que adoptaremos en esta investigación será la propuesta por el recientemente fallecido sociólogo Henry Pease y el joven historiador Gonzalo Romero (2013). Tomando como base para la periodificación los profundos cambios producidos en el seno de la estructura del Estado, propusieron una periodifiación en cuatro momentos para la historia política del siglo XX: 1) el Estado Oligárquico (1895-1956), 2) la crisis del Estado Oligárquico (1956-1968), 3) el Estado Intervencionista (1968-1990), y 4) el Estado Neoliberal (1990-2000).

Reflexionar sobre el populismo en el Perú inevitablemente supone reflexionar sobre la democracia en nuestro país. Las características de nuestra historia nacional llevaron a entender nuestro proceso democrático como inconcluso e imperfecto con profundos matices autoritarios y una ciudadanía en construcción permanente. Los estudios sobre el populismo en el país se han orientado en su mayoría a resaltar la precariedad de la institucionalidad democrática, rastrear las prácticas políticas oficiales y no oficiales entre ciudadanos y los líderes populistas, y sobre todo tratar de entender el respaldo social al autoritarismo. Por ello se han buscado sus orígenes en tiempos anteriores a su periodificación histórica (décadas de 1960 y 1980), hasta remontarse hacia finales del siglo XIX, tratando de explicar los orígenes en la época caudillista, con Nicolás de Piérola como el antecesor de la política populista.

El término populismo en nuestro país se ha relacionado con los acontecimientos de movilización de masas desde las primeras décadas del siglo XIX, y se ha caracterizado como populistas incluso a las primeras manifestaciones políticas de las agrupaciones de criollos e indígenas a favor de la independencia. Estos primeros usos del término resaltaron las apreciaciones negativas asignadas a las masas urbanas desde los tiempos de la Revolución francesa. En el Perú los temores contra la irracionalidad del populacho y sus violentas acciones fueron reproducidas en los medios de

\footnotetext{
usado por Carlos de la Torre, quien lo define en los siguientes términos: «De acuerdo con Carlos de la Torre, es una reacción nacionalista a las políticas neoliberales aplicables por los regímenes neopopulistas. En ese sentido, lo plantea como un resurgimiento del populismo clásico de los años 60 , con las mismas retóricas nacionalistas y antiimperialistas, glorificación del pueblo y uso de manifestaciones masivas para demostrar apoyo al líder» (Alvarado, 2009, p. 104).
} 
prensa de la época desde finales del Virreinato ${ }^{18}$ y en los primeros años de la joven República peruana.

Esta partida de nacimiento del uso del término en la historia políticosocial de nuestro país será complementada por las imágenes idealizadas y satanizadas de los caudillos militares, que con sus prácticas políticas clientelares y su forma patrimonialista de disponer de los recursos del Estado, serán vistos como los predecesores de la política populista en el país. Apresurada o no esta apreciación sobre las prácticas políticas caudillistas, un hecho indiscutible dentro de la caracterización del fenómeno populista es su tendencia autoritaria. La historiografía nacional sobre el particular ha conceptualizado este rasgo del periodo de nuestra joven república atribuyéndole ser el origen de la «tradición autoritaria» ${ }^{19}$ de nuestra política nacional. Con esta definición se explicaba, de algún modo, la tendencia de la población a legitimar gobiernos marcadamente autoritarios, con la tendencia de la élite dirigente de respaldar golpes de Estado y, en cierta medida, el desprecio de la ciudadanía por la institucionalidad democrática.

\section{Conclusiones}

1. Históricamente existe un miedo de la élite dominante a la aparición de líderes carismáticos que modifiquen la estructura social del país y el modelo económico, por lo cual se hace necesario descalificar a las tendencias contrarias con el rótulo populista, relacionado con prodigalidad económica y autoritarismo.

2. Al haber primado el análisis del «líder carismático» y el impacto de sus políticas en la masa popular, se ha dejado de lado el análisis de lo que llama Laclau la articulación de demandas, solo posible al analizar y entender como está articulada la sociedad con su sistema político. En este sentido, el tema ha sido abordado partiendo de la confrontación del líder carismático con el sistema imperante. Si bien esto es válido a nivel discursivo, el líder carismático se mueve dentro de un diseño institucional y electoral. Más allá del nivel discursivo, existe una realidad material que necesita articularse, una realidad material que hay que entender para influenciar en ella y construir desde allí lo político.

3. El debate sobre el populismo en nuestro país se ve entorpecido por dos motivos: a) Los medios de comunicación dominan en la actualidad el debate y ellos en esencia difunden una perspectiva negativa, y b) la izquierda académica en nuestro país, si bien valora los aportes del

18 Sobre el particular, puede consultarse Rosas Lauro, C. (2008). El impacto de la Revolución francesa en el Perú, 1789-1808. Lima: Fondo Editorial de la Pontificia Universidad Católica del Perú e Instituto Francés de Estudios Andinos.

19 Este fue el término que acuñó el investigador estadounidense David Palmer y que difundió el historiador peruano Alberto Flores Galindo. 
populismo, mantiene sus distancias en cuanto depositan demasiado protagonismo al líder carismático y no a un partido. Además de ello, tanto los medios de comunicación como las izquierdas entienden al electorado como irracional, pasional y poco preparado para actuar políticamente sin la tutela de vanguardias políticas e intelectuales.

4. No debe analizarse al populismo como una opción contraria a la democracia. Muy por el contrario, podríamos decir que es todo aquello que no nos gusta de la democracia (o al menos a la élite política) y, por tanto, constituye una forma válida de hacer política. Supone un constante cambio de las reglas de juego de la política, motivado por la presión popular y sus cambiantes necesidades. El populismo cumplió un rol histórico de ampliación de derechos ciudadanos, y constituye en la actualidad un modo de articulación de demandas que pueden conseguir cambios profundos y necesarios en nuestra sociedad. Los riesgos del autoritarismo son evidentes, pero ese es el riesgo de vivir en democracia, y a mejor informados sobre la naturaleza de los problemas que enfrentamos, mejor preparados estaremos para elegir las soluciones adecuadas. Eludir el debate nunca ha sido ni es una buena alternativa. Quisiera finalizar estas líneas con una cita algo extensa de Chantal Mouffe (1999, p. 11), quien describe acertadamente el contexto político actual:

En este final de siglo las sociedades democráticas se encuentran ante un conjunto de dificultades y muy mala preparación para afrontarlas. Los múltiples gritos de alarma ante los peligros del populismo o de un posible retorno del fascismo son señales del creciente desasosiego de una izquierda que ha perdido su identidad, y que, al no poder pensar en términos de adversario, busca desesperadamente un enemigo que pueda devolver una apariencia de unidad. Incapaz de comprender las pasiones en política y la necesidad de movilizarlas con vistas a objetivos democráticos, acusa a los demás de jugar con la emoción contra la razón. En lugar de prestar atención a las demandas sociales y culturales que se le escapan, prefieren agitar ciertos fantasmas con la idea de poder así exorcizar los supuestos demonios de lo irracional [las cursivas son nuestras]. 


\section{REFERENCIAS BIBLIOGRÁFICAS}

Alvarado Chávez, M. (2009). La invención del etnocacerismo: populismo radical en el Perú (tesis de maestría inédita). Pontificia Universidad Católica del Perú, Lima.

Barr, R. (2003). The Persistence of Neopopulism in Peru? From Fujimori to Toledo. Third World Quarterly, 24(6), pp. 1161-1178.

Barrera Bernuy, J. (2004). Las elecciones de 1912. La Guerra de los Panes. Historia Total, 1, pp. 109-128.

Bazán Pantoja, R. (2000). El fracaso del proyecto populista de Billinghurst. Ukupacha, 2, pp. 101-108.

Blanchard, P. (1982). The Origins of the Peruvian Labor Movement, 18831919. Pittsbourgh: University of Pittsbourgh Press.

(1977). A populist precursor: Guillermo Billinghurst. Latin American Studies, 9(2), pp. 251-273.

Candela Jiménez, E. I. (2013). El régimen de Óscar R. Benavides (1933-1939): ¿una experiencia populista? Definiciones y nuevos planteamientos en torno a su accionar político (tesis de maestría). Pontificia Universidad Católica del Perú, Lima.

Castillo Ochoa, M. (1990). El populismo conservador. Sánchez Cerro y la Unión Revolucionaria. En Adrianzén, A. (Ed.). Pensamiento político peruano 1930-1968 (pp. 47-76). Lima: Desco.

Chaupis Torres, J. (2012). El califa en su laberinto: esperanza y tragedia del régimen pierolista (1879-1881). Lima: Universidad Nacional Mayor de San Marcos y Seminario de Historia Rural Andina.

(2007). El proyecto político de Nicolás de Piérola (1879-1881). Historias. Revista de la Asociación de Historia, Sociología y Ecología, 2, pp. 93-109.

Coronado del Valle, J. (1984). El gobierno en Billinghurst y la emergencia de la clase obrera 1912-1914. Lima: Facultad de Ciencias Sociales de la Universidad Nacional Mayor de San Marcos.

Cotler, J. (1969). El populismo militar como modelo de desarrollo nacional: el caso peruano. Lima: Instituto de Estudios Peruanos.

Crabtree, J. (2000). Populisms old and new: the Peruvian case. Latin American Research, 19, pp. 163-176.

(1998). Neopopulism and the Fujimori Phenomenon. Londres: University of London.

(1997). Populismo y neopopulismo. Apuntes, 40, pp. 97-109. 
Peisa.

(1992). Alan García en el poder. Perú 1985-1990. Lima:

Drinot, P. (2001). El comité sanchezcerrista de Magdalena del Mar, un ensayo de microhistoria política. Revista del Archivo General de la Nación, 23, pp. 333-353.

Franco, C. (1990). La plebe urbana, el populismo y la imagen del alumbramiento. Socialismo y Participación, 52.

González, O. (2009). Guillermo E. Billinghurst: Transfronterizo y multifacético. Socialismo y Participación, 107, pp. 43-52.

(2007). Los orígenes del populismo latinoamericano.

Una mirada diferente. Cuadernos del CENDES, 66, pp. 75-104.

(2005). Los orígenes del populismo en el Perú. El gobierno de Guillermo E. Billinghurst (1912-1914). Lima: Biblioteca Nacional del Perú.

González Miranda, S. (2000). Guillermo Billinghurst Angulo: una biografía regional. Recuperado de www.revistacienciasociales.cl/archivos/revista10/word/revista10_articulo1.doc

Huamán Valladares, M. J. (1974). El APRA de 1930 a 1945: ¿movimiento populista? (tesis de bachillerato). Pontificia Universidad Católica del Perú, Lima.

Jacobsen, N. (2014). Populism Avant La Lettre in Peru: Rebuilding Power in Nicolás de Piérola's Mid-Career, 1884-1895. Jahrbuckh für Geschichte Lateinamerikas / Anuario de Historia de América Latina, 51, pp. 35-58.

Leceta, H. (2001). Las multitudes políticas de Lima y Callao de 1912 y la elección de Guillermo Billinghurst (tesis de doctorado). Pontificia Universidad Católica del Perú, Lima.

Lynch, N. (2009). El argumento democrático sobre América Latina. La excepcionalidad peruana en perspectiva comparada. Lima: Fondo Editorial de la Facultad de Ciencias Sociales de la Universidad Nacional Mayor de San Marcos.

(2000). Política y antipolítica en el Perú. Lima: Desco.

Martín Sánchez, J. (1996). Perú chino a chino: Discusión inicial en torno al líder populista y la nueva política. Socialismo y Participación, 75, pp. 93-106.

Molinari Morales, T. (2009). El fascismo en el Perú. La Unión Revolucionaria 1931-1936. Lima: Fondo Editorial de la Facultad de Ciencias Sociales de la Universidad Nacional Mayor de San Marcos.

Palmer, D. S. (1980). Peru: the Authoritarian Tradition. Nueva York: Praeger.

Panfichi, A. y Sanborn, C. (1997). Fujimori y las raíces del neopupulismo. En Tuesta, F. (Ed.). Los enigmas del poder: Fujimori 1990-1996. Lima: Fundación Friedrich Ebert. 
(1995). Democracia y neopopulismo en el Perú contemporáneo. Márgenes, 13-14, pp. 43-67.

Pease, H. (1988). Democracia y precariedad bajo el populismo aprista. Lima: Desco.

Salinas Sánchez, A. (2014). La época del «pan grande» Billinghurst presidente 1912-1914. Lima: Universidad Nacional Mayor de San Marcos y Seminario de Historia Rural Andina.

Stein, S. (1980). Populism in Perú. The emergence of the Masses and the Politics of Social Control. Madison: Wisconsin Press.

Torrejón Muñoz, L. A. (2010). Rebeldes republicanos: la turba urbana de 1912. Lima: Red para el Desarrollo de las Ciencias Sociales en el Perú.

(2006). Lima 1912: Estudio social de un motín urbano (tesis de licenciatura). Pontificia Universidad Católica del Perú, Lima.

(1995). Lima 1912: El caso de un motín popular urbano. En Panfichi, A. y Portocarrero, F. (Eds.). Mundos interiores: Lima 1850-1950 (pp. 315-339). Lima: Universidad del Pacífico.

Ubilluz, J. C. (2010). La política del síntoma. De la democracia radical al populismo (y de vuelta a la lucha de clases). En Portocarrero, F., Ubilluz, J. C. y Vich, V. Cultura política en el Perú (pp. 291-317). Lima: Red para el Desarrollo de las Ciencias Sociales. 